\title{
Research on the Capability Maturity Model of Digital Library Knowledge
}

\section{Management}

\author{
Zhiyin Yang ${ }^{12, a}$, Ruibin Zhu ${ }^{1, b}$,Lina Zhang ${ }^{1, c^{*} \text { corresponding author }}$ \\ ${ }^{1}$ Information and Technology College , Jilin Agricultural University \\ ${ }^{2}$ School of Computer Science and Information Technology, Northeast Normal University \\ Jilin, China \\ a23133124@qq.com, b18943930551@qq.com, c*13826208@qq.com
}

Keywords: digital library; knowledge management; key process areas; maturity levels

\begin{abstract}
This paper builds capability maturity model of digital libraries based on the capability maturity model for software and sets up knowledge management maturity level according to the characteristic of digital libraries. Each level sets key process area, then gradually improves the digital libraries knowledge management by means of key practice. It will elevates the maturity level from junior to senior which will meet users' demands and realize the sustainable development of digital libraries.
\end{abstract}

\section{Introduction.}

As the main body of the data service in today's mainstream, the digital library is along with the rapid development of information technology and network technology. For the knowledge management of digital library, the experts and scholars has carried on the discussion of the multi-level three-dimensional which refer to the traditional library's knowledge management combined with the inherent characteristics of digital library. But the research on the maturity model of the digital library's knowledge management ability is not enough. To that end, based on the capability maturity levels of software industry, this paper establishes a digital library knowledge management capability maturity model, in order to improve and perfect the knowledge management ability of digital library.

\section{Literature review}

2.1 Knowledge Management. At present, there are two kinds of understanding on Knowledge management: One kind of knowledge management is based on information management, construction of the object and content of knowledge management with the model of information management, to the extension and development of information management; The other kind of understanding that, knowledge management gives people knowledge organization and innovation process, and pays attention to the development and cultivation of people's creative thinking and ability, pay attention to the establishment of sustainable development from the system and organization innovation environment, pay attention to the optimization management of talent structure and use[1]. Knowledge management has a variety of functions, the sustainable development of the organization can be realized by using it, improve the quality of staff and work efficiency, enhance customer satisfaction, improve the operation performance of the organization and so on[2].

2.2 Capability Maturity Model .Capability maturity model is a kind of the definition of software in software development, implementation, measurement, control and improvement are divided into different stages, and used to assess their ability to develop and improve the quality of the method, emphasizes the gradual improvement and continuous improvement of management level [3]. The Software Engineering 
Research Institute of Carnegie Mellon University (Mellon Carnegie) has put forward software capability maturity model in the software industry from the perspective of software process capability (Capability Maturity Model for Software, CMM- SW), subsequently in the United States and the world to be implemented and popularized. It has almost become the industry standard for software engineering in the world, and is also one of the most successful models in the world today. The model is generally divided into five levels, namely five maturity, each of which has its own key process of maturity, the key process area to guide the key practice to achieve the requirements of their respective maturity.

Other capability maturity models are K-PMMM, P3M3, etc.. K-PMMM model is proposed by the famous American consultant and trainer Kerzner Harold, from the point of view of project management strategic planning, a special questionnaire survey method was adopted, and some objective self assessment questions were given at different levels. By answering these questions, it can analyze, organize and judge the problems which existing in the project management, and provide the basis for improving and improving the level of project management[4]. P3M3 was released by the Ministry of UK Commerce in 2005, is a project management maturity model that can be applied to a number of industries. Using P3M3 to assess the organization's project management capabilities, you can effectively identify to improve the management process that you need, to help organizations improve performance better[5].

\section{Hierarchical Division of Knowledge Management Capability Maturity Model in Digital Library}

The capability maturity model can make the knowledge management of the digital library in accordance with the requirements of knowledge management, to collect, organize, study and make use of, and to organize the members of business skills training, focus on the overall development of digital library, so that it has become a cultural platform, education platform and resource center. This paper takes the CMM as the foundation, combined with the characteristics of knowledge management in digital library, constructing the knowledge management capability maturity model of digital library. The model of digital library knowledge management ability from low to high is divided into 5 levels: Original level, repeatable level, general level, management level and innovation level, and set each level should have their own characteristics and capacity requirements.

3.1 Original Level. The knowledge management of the digital library in the Original level does not have any conscious control of the process of knowledge, and no specific definition of the process of knowledge management, work clueless. Some of the "success" of knowledge activities only by luck, relying solely on the personal approach and efforts. Finding new and transfer levels is too low or even impossible to carry out, Librarian does not know and understand knowledge management and ideas, the digital library is not aware of the establishment of knowledge intensive tasks for the survival and development of the digital library, and there is no special department or organization responsible for the relevant work of knowledge management. Therefore, the role of knowledge management in digital library is very limited.

3.2 Repeatable Level. Digital library from the leadership to the staff level at the repeatable level, from librarian to user, has recognized the important role of knowledge management to its development, to begin to understand the meaning and value of knowledge management. Digital librarians in the work activities to learn basic skills, using knowledge management to carry out a simple planning and management. Active for a variety of information resources development and processing, can do multiple information retrieval. Some certain parts of the business process has been defined as knowledge management tasks, has the related 
knowledge management unit, and higher level of attention, there are some incentive mechanism for librarians, in order to make their enthusiasm for work.

3.3 General Level. To achieve the digital library general level reached the basic level in all aspects, in the basis of acquiring and processing information through knowledge mining unit and set some hidden structures on, make the externalization of tacit knowledge. There is a systematic and scientific management, and given the information technology support, improve the system of foreign invasion defense, which tend to be stable and reliable. Sharing between collection is higher, the literature forms, the updating of knowledge, spread more rapidly and widely. Librarians understand and actively participate in the activities of knowledge management, to organize the training, the embassy staff receive detailed knowledge; To spontaneous cooperation, the idea of knowledge management into the organizational culture in the digital library, in order to achieve the purpose of value-added knowledge.

3.4 Management Level. To achieve the knowledge of digital library management level management has been standardized, can master every aspect of knowledge management, has been integrated into the learning organization. The digital library within the scope of all parts of knowledge may be obtained can be applied to the new project and environment. In general, the sharing of knowledge and knowledge utilization can be done at the same time. In the knowledge service management, pay attention to the user experience, the user must have personal knowledge management content, librarians should also from the data for the evolution of "network administrator guide". Have a good knowledge of the evaluation system, especially the choice to do a set of evaluation criteria and evaluation tools. In the knowledge of marketing, pay attention to establish the structure of marketing relationship with the user, allowing users to become the library knowledge product long-term, loyal consumers. To protect their intellectual property, and do not infringe intellectual property rights.

3.5 Innovation Level. Facing the constantly changing requirements of knowledge management, the digital library has the ability to adjust and adapt, and keep the maturity level, have a painstaking development after a breakthrough. the traditional classification method to improve and develop good technical management reform, the hardware equipment to timely upgrade etc.. Digital library at this level is not only to calmly deal with the opportunities and challenges from various aspects, but also on the basis of innovation, so called innovation level. Innovation is the highest level of knowledge management maturity model, at this level of organization members mutual sharing and using of all of the explicit knowledge and tacit knowledge, absorption and utilization, create new knowledge, and innovation oriented organizational culture, and constantly enhance the core competitiveness of the organization, ultimately to achieve organizational goals to maximize its revenue. Then need to follow the rule is: in the maintenance of existing knowledge management capability maturity, enjoy knowledge management brings gains at the same time, make the greatest efforts to improve their own level, break the maturity model and the ability to enter into a more advanced capability maturity environment.

\section{Key Process Areas of Digital Library Knowledge Management Capability Maturity}

4.1 Division of the Key Process Area. Digital library knowledge management capability maturity model (CMM) of each level is composed of a number of key process areas, preliminary can be divided into five grades of 18 process area. Table I lists the key process areas of each maturity level. 
TABLE I: KEY PROCESS AREA OF EACH MATURITY LEVEL

\begin{tabular}{|c|c|c|}
\hline maturity level & Key process area & Number \\
\hline Original level & ----------- & none \\
\hline $\begin{array}{l}\text { repeatable } \\
\text { level }\end{array}$ & $\begin{array}{c}\text { Knowledge Processing } \backslash \text { Leadership attention } \backslash \text { Knowledge } \\
\text { Requirements Management } \backslash \text { Credibility Awareness } \backslash \text { Knowledge } \\
\text { Acquisition }\end{array}$ & 5 \\
\hline general level & $\begin{array}{c}\text { Knowledge Organization } \backslash \text { security complete } \backslash \text { Content Quality } \backslash \\
\text { Librarian training } \backslash \text { resource utilization }\end{array}$ & 5 \\
\hline $\begin{array}{l}\text { management } \\
\text { level }\end{array}$ & $\begin{array}{l}\text { Knowledge Marketing } \backslash \text { Knowledge Service } \backslash \text { Intellectual } \\
\text { Property Rights } \backslash \text { User profile } \backslash \text { feedback evaluation }\end{array}$ & 5 \\
\hline $\begin{array}{c}\text { innovation } \\
\text { level }\end{array}$ & $\begin{array}{l}\text { Knowledge Innovation } \backslash \text { technological innovations } \backslash \\
\text { Quantitative cost-benefit analysis }\end{array}$ & 3 \\
\hline
\end{tabular}

4.2 Implement Key Process Area. For the original level, there are no any process area. According to the different characteristics of different levels, from the repeatable level to level innovation and formulate different key process areas.

For the repeatable level, because the effect of knowledge management is delayed, it is hard to see economic and practical effect in the short term。Therefore, knowledge management in a cluster is real and development, must first get the attention of the leadership to understand the demand for knowledge organization, the most direct embodiment is to set up knowledge management department and arrange qualified competent personnel working here. In the knowledge acquisition, it can be divided into external and internal knowledge acquisition. Internal knowledge exists in digital library, which in information documents and data warehouse form, one of the most important experience and skills of the internal knowledge is librarians. Acquiring external knowledge mainly gets through the connections between people and the media. To note here that the question of whether there are any credible knowledge and between the digital library librarian should have a deep understanding of the related problems, when it is necessary to determine the credibility of some specific knowledge, and use a variety of forms. After having the knowledge ,how to carry on the processing of knowledge is the key steps of this phase, after processing through a variety of methods of knowledge to the next stage of knowledge management.

General level of key process area of librarians' training, because the institutionalization of training is digital library administrators' job which in this level should be prior . Training includes knowledge about digital library own which related business knowledge and knowledge management. In respect of knowledge representation, should be characterized by a variety of forms, such as data, rules and maps, etc., so that digital librarians and users can easy to acquire. Knowledge expression is also focus on the category of artificial intelligence and cognitive science. For knowledge own, in determining the authenticity, through modern storage technology and encryption technology to improve knowledge of integrity, security, to ensure the quality of knowledge.

In the management level, it not only attaches importance to knowledge own, but also deepens knowledge of the user service. Establish the user archives, accept user feedback evaluation, it often can firmly grasp the user feel, further meet the demand of user knowledge, in order to realize the further increase of digital library. Use the Internet for information retrieval and query, through information gathering, information filtering, information classification, the essence of extraction process; Use interactive methods provide service for network users. Knowledge marketing gets through effective ways and means of knowledge dissemination, and the digital library possesses the user valuable knowledge to transmit to potential users, then gradually formed the cognition to the digital library brand and product, for potential users will eventually translate into users of various marketing activities, through this kind of 
behavior can make digital books have great benefits. Digital library must keep in mind that knowledge is the capital, pay attention to the protection of intellectual property rights, the fair use of explicit knowledge, the use of access control technology, data encryption, digital watermark technology, information technology and other technical measures to establish a safety barrier. Using client authentication technology (CA) and set the billing software, use the information included in the web site of the users in the system automatically set up account, measures such as strengthening digital library as the main body of public welfare propaganda and the cultivation of intellectual property rights awareness of users.

Innovation level contains key process areas include knowledge innovation degree, quantitative analysis of cost benefit and technical innovation. What about the knowledge innovation, is one of the important indexes of measuring organizational knowledge innovation ability. The innovation of the digital library, including concept innovation, technology innovation, management innovation and service innovation, and so on. Quantitative analysis between cost and benefit of cause and effect, so that the relationship between input and output of a scientific estimates as much as possible. The reform of the technology is very important for the organization, and sometimes even affect the core competitiveness of the organization.

\section{Conclusion}

The process of knowledge management of digital library can be divided into five maturity levels: The original level, repeatable level, general level, management level and innovation level. Each grade has key process areas and practices of their own. With the establishment of maturity model and the evaluation index system, can be of any knowledge management of digital library development process of maturity assessment and analysis, determine the maturity level, the analysis of the existing problems, causes of problems. And put forward the measures should be taken for the development of digital library to provide targeted policy recommendations.

\section{Acknowledgment}

This work was supported by the Scientific Research Fund of Jilin Agricultural University under Grant No. 2015044、 No. 201422 and Key Projects in Education and Teaching Research of the Education Department of Jilin Province under Grant " The Construction and Implementation Research of University Education Scientific Literature Information Supporting Platform in Jilin Province ".

\section{References}

[1]G.P. Qiu,Science of knowledge management.Beijing, Science and Technology Literature Press,2006.

[2]L.H. Lin, J.H Sun, Knowledge management. Beijing, Peking University Press,2011

[3]Y.L. Mu, "Library Knowledge Management Capability Evaluation and Empirical Analysis,” Information studies: Theory \& Application, vol.35, issue 3, pp. 83,2012.

[4]T.Cai, "Knowledge Management Maturity Model Study," Jornal of Information , vol.25, issue 4, pp. 29,2006 .

[5]H.C Jiang, M.S. Qiang, "Comparative study of four Project Management Maturity Model," Project Management Technology, vol.11, issue 7, pp. 18,201 